\title{
Surgical endocrinology—update 2010
}

\author{
Bruno Niederle
}

Received: 19 July 2010 /Accepted: 22 July 2010 /Published online: 16 August 2010

(C) Springer-Verlag 2010

"In the ensuing three-quarters of a century, the science called 'surgical endocrinology' has come a long way and currently, this rather recently adopted surgical child is assuming just recognition by the more established members of the surgical family. The modern surgical endocrinologist has been trained to visualise and manage the endocrine system as a whole and should feel equally comfortable dealing with endocrine problems in the neck, pancreas, gastrointestinal tract, or adrenal glands." It was J. A. van Heerden ([21] World J Surgery), who-for the first timesummarised the aspects of "Surgical Endocrinology" (synonym: Endocrine Surgery) in 1982 shortly after the memorable foundation of the International Association of Endocrine Surgeons in 1979 in San Francisco, which acts as an umbrella group for endocrine surgeons worldwide. Besides The "American Association of Endocrine Surgeons", the "Asian Association of Endocrine Surgeons" and the "Australian and New Zealand Association of Endocrine Surgeons", just to name a few, the "European Society of Endocrine Surgeons" (ESES; www.eses.cc) founded in 2003 in Vienna, is the well-established representative of European surgeons who have a specialist interest in surgery of the endocrine glands ([9] Langenbecks Arch Surg).

"Surgical Endocrinology/Endocrine Surgery" is a new, rapidly growing surgical sub-specialty. ESES advocates the development of this discipline promoting the exchange of knowledge and improving the techniques in endocrine

B. Niederle $(\bowtie)$

Section of Endocrine Surgery, Division of General Surgery,

Department of Surgery, Medical University Vienna,

Währinger Gürtel 18-20,

A-1090 Wien, Austria

e-mail: bruno.niederle@meduniwien.ac.at surgery to maintain high standards in the clinical practice, in education and in research. Therefore, ESES organises meetings, symposia, workshops and courses.

Recently, more than 300 surgeons with special interest in this field gathered in Vienna to present and discuss individual experience and new developments. A total of 231 abstracts were submitted from all parts of the world. After a first selection, 217 blinded abstracts were reviewed by members of the "Executive Committee" and of the "Research and Education Committee". The 40 best-scored abstracts (throughout all topics of "Endocrine Surgery") were accepted for presentation. The best 19 peer-reviewed articles on clinical and experimental endocrine surgery are incorporated in this issue.

A careful preoperative diagnostic workup is the basis for successful treatment of various thyroid diseases. However, they are not always uneventful. Fine Needle Aspiration Cytology (FNAC) is a widely used diagnostic tool to assess thyroid lesions, with low morbidity. However, neck hematomas following FNAC are reported. Only very few cases of massive bleeding resulting in acute airways obstruction have been described up to now. Rapid intervention is mandatory to avoid life-threatening complications ([4] Langenbecks Arch Surg, this issue).

Real-time ultrasound elastography (USE) is a new technique for evaluation of tissue stiffness. It was postulated that malignancy shows a low strain. USE seems a useful adjunctive tool in the non-invasive workup of thyroid nodules. A low-strain value needs surgery while a high strain predicts a benign histology. The evaluation of thyroid nodules with UES might lead to different therapeutic approaches of thyroid nodules in the future ([23] Langenbecks Arch Surg, this issue).

The application of various molecular markers may help to better distinguish benign and malignant thyroid tumours. 
Immunohistochemistry for CD56, HBME-1, COX-2, Ki$67, \mathrm{p} 53$, E-Cadherin (E-CAD) was performed in benign and malignant thyroid lesions. The panel consisting of three markers: HBME-1, E-CAD and CD56 can be recommended as an adjunct to conventional morphological criteria. HBME-1 is found in malignant lesions only and is the most sensitive and specific single marker in papillary thyroid carcinoma (PTC). Decreased expression of E-CAD and CD56 distinguishes PTC from follicular tumours (follicular adenoma (FA) and follicular thyroid carcinoma (FTC)). Both FA and FTC are characterised by high expression of E-CAD and CD56. The practical use of Ki-67 is difficult due to low values. The role of adhesion factors in thyroid malignancies may be superior in comparison with cell proliferation ([19] Langenbecks Arch Surg, this issue).

BRAF mutations and RET or NTRK1 rearrangements were identified as causing events that drive the malignant transformation of the thyroid follicular cell. Further evidence that patients harbouring BRAFV600E-positive PTCs may experience an unfavourable course of the disease compared to patients with tumours carrying other genetic alterations was presented ([18] Langenbecks Arch Surg, this issue).

Approximately 5\% of differentiated thyroid carcinomas are of familial origin. These familial nonmedullary thyroid carcinomas have an increased risk of multifocal disease and lymph node involvement. Consequently, higher recurrence rates and decreased disease-specific survival rates are described. The surgical strategy is discussed controversially. In this retrospective, multicentre analyses of 41 patients revealed an early onset of small, mostly papillary thyroid carcinomas and an increased risk of multifocality and lymph node involvement. Total thyroidectomy and systematic neck dissection are recommended together with radioiodine ablation. Clinical screening for first-degree relatives should start at age 18 ([12] Langenbecks Arch Surg, this issue).

There were no significant differences comparing the pain scores after minimally invasive video-assisted thyroidectomy and conventional thyroidectomy. Also, the postoperative analgesic consumption was the same. The length of the skin incision seems not to influence the perception of pain after thyroid surgery ([1], Langenbecks Arch Surg, this issue)

Postoperative lymphatic leakage (chyle fistula or chylous leakage) following thyroid surgery may represent a management problem with potential morbidity, psychological and economical impact. Reliable criteria to predict outcome of conservative versus surgical treatment in clinically evident lymph fistula are rare. Twenty-nine patients identified with postoperative clinical evidence of lymph fistulas following thyroid surgery (incidence $0.5 \%$ ) were analysed retrospectively. Conservative and surgical man- agement strategies for high- ( $>300 \mathrm{ml} /$ day $)$ and low-output $(<200 \mathrm{ml} /$ day $)$ lymph fistulas are different. Low-output fistula justifies conservative treatment (fasting, parenteral nutrition) whereas high-output fistulas longs for surgical intervention (ligation, suture, muscle flap, fibrin glue, hemostyptic fleece - combination of two or more). Lymph fistulas cause significantly prolonged hospital stay, possible critical clinical decay and unfavourable cosmetic and oncologic outcome ([15] Langenbecks Arch Surg, this issue).

Vitamin D deficiency has a higher prevalence as generally assumed, is often not recognised and should be taken into consideration in all ages. The vitamin D endocrine system is a potent modulator of parathyroid function. It is well known, that vitamin D deficiency results in asymmetric parathyroid hyperplasia and "mild" reactive hyperfunction resulting in an increase of parathyroid hormone and is reversible supplementing vitamin D. Not recognising this relation may lead to unnecessary parathyroid gland resection during thyroidectomy. A significant difference in both individual gland volume and variation in parathyroid gland volume according to D3 levels were documented. The variation in gland volume within subjects is greater in those with vitamin D3 deficiency. Asymmetric parathyroid glands may be documented in normal and decreased D3 levels. In patients with D3 levels $<30 \mathrm{ng} / \mathrm{ml}$ (by definition: vitamin $\mathrm{D}$ deficient patients) the asymmetrical parathyroid hyperplasia was more pronounced. The data suggest that parathyroid enlargement in response to vitamin D3 deficiency is not uniform amongst all four parathyroid glands: one significantly enlarged gland in patients may be revealed. From the practical point, this is an interesting and important analysis demonstrating that importance of D3 levels before thyroid surgery, sometime misleading the surgeon to additional parathyroid surgery. It should be emphasised that the knowledge of calcium and PTH levels help to interpret the vitamin D levels and may influence the surgical strategy ([14] Langenbecks Arch Surg, this issue).

Over the last years, the clinical spectrum of primary hyperparathyroidism (PHPT) has changed from severe classical clinical to milder, sub-clinical manifestations. Some studies suggest that this change in clinical pattern also implies lower preoperative biochemical parameters and smaller adenomas. The preoperative imaging of small adenomas may be more difficult, possibly increasing the risk of surgical failure. Analysing the years 1990 to 2007, there was a significant trend to operate patients with lower preoperative serum calcium levels. In women, the adenoma weight decreased. This trend could potentially lead to decreased sensitivity in preoperative localization procedures ([2], Langenbecks Arch Surg, this issue)

Successful parathyroidectomy in PHPT is followed by a significant decrease in the severity of clinical symptoms. 
However, some argue that such benefits are only shortlived. Symptomatic benefits persist for at least 1 year after parathyroidectomy in at least two thirds of patients with PHPT ([8] Langenbecks Arch Surg, this issue).

Endemic goitre regions are disseminated in Europe. According to population-based surveys, PHPT is now considered as the third most frequent endocrinopathy (after diabetes mellitus and thyroid diseases). Therefore, coexisting thyroid nodular disease in patients with PHPT may become a diagnostic problem influencing the negatively the sensitivity of preoperative localization studies. In patients with coexisting thyroid disease but thyroid surgery not needed, MIBI scintigraphy contributes to the detection of a solitary adenoma. When thyroid resection is required, MIBI imaging is often negative ([7] Langenbecks Arch Surg, this issue).

The three most often used surgical accesses for selective, minimally invasive parathyroidectomy are the open "miniincision" performed through a medial or lateral approach, the "video-assisted" and the "endoscopic" with gas insufflation. Besides the original description ([11] Langenbecks Arch Surg) a large single-centre series using the totally endoscopic lateral approach for selective, minimally invasive parathyroidectomy, showing good postoperative shortterm results with a high rate $(28 \%)$ of conversion to open exploration, is presented ([6] Langenbecks Arch Surg, this issue)

Parathyroid exploration for (very rare) located ectopic, mediastinal hyperfunctioning glands can be performed by a transcervical approach, by sternotomy, thoracotomy and recently by thoracoscopy and mediastinoscopy. For upper mediastinal enlarged parathyroids the conventional transcervical route may achieve satisfactory results. More extended exporation by sternotomy is effective, but should be limited because of invasiveness and increased morbidity. In case of deep and lower, well localised hyperfunctioning mediastinal parathyroids, videoassisted approaches represent a less-invasive, effective and safe alternative to sternotomy or thoracotomy and might be the technique of choice ([13] Langenbecks Arch Surg, this issue)

Whether intraoperative neuromonitoring (IONM) can prevent permanent damage to the recurrent laryngeal nerve during extended cervical explorations is still a matter of ongoing discussion. The definitions of "normal" parameters and a "standardisation of the technique" seem prerequisites for the interpretation of quantitative changes of IONM during thyroid surgery to better predict postoperative vocal cord function. Vagal nerve stimulation is essential recognising inferior laryngeal nerve lesions. Issues that have been overlooked in the literature, particularly in terms of prospective approaches, are the topographic relationship of the vagal nerve to the carotid and jugular vessels as well as the neurophysiology of the vagal nerve and inferior laryngeal nerve. Vagal nerve identification and stimulation seems feasible in all patients and does not increased morbidity or operative time. Mean amplitudes of EMG signals obtained from vagal nerve stimulation is lower than signals obtained after direct stimulation of the inferior laryngeal nerve. A better understanding of the variability in the vagal nerves may be useful to minimise complications and to guarantee an accurate IONM. ([4] Langenbecks Arch Surg, this issue)

Systematic data of a multicenter evaluation on quantitative IONM parameters further revealed differences between left and right vagal nerves concerning the amplitude, latency and duration of signal, gender and age. The nature of thyroid disease showed no significant influence on quantitative parameters of IONM ([16] Langenbecks Arch Surg, this issue).

The functionality of vocal folds was evaluated by ultrasound and the results correlated to the results of laryngological examination. Ultrasound imaging of the vocal folds correlated well with conventional laryngological examination and may be a minimally invasive, easily reproducible and inexpensive method of examining vocal cord functionality early in the postoperative period. However, an analysis of a larger group of patients is necessary to evaluate and standardise the technique ([3] Langenbecks Arch Surg, this issue).

A solitary tumour, unilateral or bilateral adrenal hyperplasia may cause primary aldosteronism. Prior to treatment, most patients have to undergo adrenal venous sampling to confirm unilateral or bilateral hormonal secretion. 11Cmetomidate positron emission tomography is a highly sensitive method for detecting and categorising even small adrenocortical tumours in primary aldosteronism. Dexamethasone suppression was unable to increase the tumourto-normal-adrenal ratio to further facilitate detection of small adenomas as an alternative to adrenal venous sampling ([10] Langenbecks Arch Surg, this issue).

Endoscopic procedures are the new "golden standard" for the surgical treatment of most adrenal lesions. In a national Spanish survey performed in 2008, data were collected including the type of hospital, yearly hospital volume of procedures, location studies, preoperative preparation, indications, surgical approach, instruments used and results in terms of morbidity and overall hospital stay. Also, comparisons between results of high (ten or more procedures in 2008) or low-volume centres (nine or less adrenalectomies in 2008) and surgeons were performed. The most frequent indication for surgery were pheochromocytoma $(23.2 \%)$; adrenocortical malignancy was rare (3.8\%). Endoscopic techniques were performed in $83.9 \%$ of patients with a conversion rate to open surgery of $9.4 \%$. As expected, high-volume centre more often treated adrenal tumours endoscopically with lesser morbidity compared to 
low-volume departments ([22] Langenbecks Arch Surg, this issue).

The European Network for the Study of Adrenal Tumours (ENSAT) aims to improve the understanding of the genetics, tumourigenesis and hypersecretion in patients with adrenal tumours and associated familial syndromes. It also aims to improve the prediction of recurrence and the management of malignant adrenal tumours. Besides various staging systems for adrenocortical carcinoma, ENSAT introduced a new staging system. Incorporating tumour grading the ability to more accurately predict time to recurrence and death should be improved. Tumour grade plays a significant role in the outcome of patients with ACC. High-grade tumours $(>20$ mitoses per 50 high-power field) are associated with shorter disease free intervals and shorter overall survival. The proposed modification of the ENSAT staging system allows for incorporation of tumour grade when predicting overall survival ([17] Langenbecks Arch Surg, this issue).

Information on optimal time to treat pancreatic neuroendocrine tumours (PNETs) comes mostly from small, retrospective, uncontrolled studies. Analysing 262 newly diagnosed, histologically proven PNETs collected in 24 Italian centres, the results of the study once more emphasise that, as expected, surgical resection represents the cornerstone treatment of PNETs. A curative resection was performed more frequently in asymptomatic, small, non-metastatic, benign and at uncertain behaviour tumours, with low Ki67 values ([24] Langenbecks Arch Surg, publication in process; surgical treatment of pancreatic endocrine tumours in Italy: results of a prospective multicenter study on 262 cases).

Endocrine surgery is a growing field. A close cooperation with clinical endocrinologist, oncologists, radiologists/ nuclear medical physicians and pathologists helps to stimulate a "European School of Endcorine Surgery". To ensure the flourishing of "Endcorine Surgery", efforts should be made to recruit bright, enterprising and diverse residents early in their careers. ESES and other societies in endocrine surgery have to continue organising discussion rounds and fellowship training to optimise training of successful endocrine surgeons for the future ([20] Surgery).

\section{Conflicts of interest None.}

\section{References}

1. Alesina PF, Rolfs T, Rühland K, Brunkhorst V, Groeben H, Walz MK (2010) Evaluation of postoperative pain after minimally invasive video-assisted and conventional thyroidectomy: results of a prospective study. Langenbecks Arch Surg 395. doi:10.1007/ s00423-010-0688-0

2. Almquist $\mathrm{M}$, Bergenfelz $\mathrm{A}$, Mårtensson $\mathrm{H}$, Thier $\mathrm{M}$, Nordenström E (2010) Changing biochemical presentation of primary hyper- parathyroidism. Langenbecks Arch Surg 395. doi:10.1007/ s00423-010-0675-5

3. Dedecjus M, Adamczewski Z, Brzezinski J, Lewinski A (2010) Real-time, high-resolution ultrasonography of the vocal folds- a prospective pilot study in patients before and after thyroidectomy. Langenbecks Arch Surg 395. doi:10.1007/s00423-010-0694-2

4. Dionigi G, Chiang F-Y, Rausei S, Wu C-W, Boni L, Lee KW, ; Rovera F, Cantone G, Bacuzzi A (2010) Surgical anatomy and neurophysiology of the vagus nerve (VN) for standardised intraoperative neuromonitoring (IONM) of the inferior laryngeal nerve (ILN) during thyroidectomy. Langenbecks Arch Surg 395. doi:10.1007/s00423-010-0693-3

5. Donatini G, Tiziano M (2010) Fine needle aspiration cytology for thyroid nodules is a routine and safe procedure? A series of emergency cervicotomies following FNAC. Langenbecks Arch Surg 395. doi:10.1007/s00423-010-0683-5

6. Fouquet T, Germain A, Zarnegar R, Klein M, De Talance N, Mayer JC, Ayav A, Bresler L, Brunaud L (2010) Totally endoscopic lateral parathyroidectomy: prospective evaluation of 200 patients. Langenbecks Arch Surg 395. doi:10.1007/s00423-010-0687-1

7. Gómez-Ramírez J, Sancho Juan J, Pereira JA, Jimeno J, Munné A, Sitges-Serra A (2010) Impact of thyroid nodular disease on 99mTCSestamibi scintigraphy in patients with prima hyperparathyroidism. Langenbecks Arch Surg 395. doi:10.1007/s00423-010-0680-8

8. Gopinath P, Sadler GP, Mihai R (2010) Persistent symptomatic improvement in two thirds of patients undergoing parathyroidectomy for primary hyperparathyroidism. Langenbecks Arch Surg 395. doi:10.1007/s00423-010-0689-z

9. Hamberger B (2008) Endocrine Surgery. Langenbecks Arch Surg 393:619-620

10. Hennings J, Sundin A, Hägg A,.Hellman P (2010) 11C - metomidate positron emission tomography after dexamethasone suppression for detection of small adrenocortical adenomas in primary aldosteronism. Langenbecks Arch Surg 395. doi:10.1007/s00423-010-0681-7

11. Henry JF, Defechereux T, Gramatica L, De Boissezon C (1999) Minimally invasive videoscopic parathyroidectomy by lateral approach. Langenbecks Arch Surg 384:298-301

12. Hillenbrand A, Varhaug JE, Brauckhoff M, Pandev R, Haufe S, Dotzenrath Co, Köberle-Wührer R, Hoffmann R, Klein G, Kadmon M, Negele T, Hagieva T, Henne-Bruns D, Luster M, Weber $T$ (2010) Familial nonmedullary thyroid carcinomaclinical relevance and prognosis. A European Multicenter Study. Langenbecks Arch Surg 395fs. doi:10.1007/s00423-010-0696-0

13. Iacobone M, Mondi I, Viel G, Citton M, Tropea S, Frego M, Favia G (2010) The results of surgery for mediastinal parathyroid tumours: a comparative study of 63 patients. Langenbecks Arch Surg 395. doi:10.1007/s00423-010-0678-2

14. Kirkby-Bott J, El-Khatib Z, Soudan B, Caiazzo R, Arnalsteen L, Carnaille B (2010) 25 hydroxy vitamin D deficiency causes parathyroid incidentalomas. Langenbecks Arch Surg 395. doi:10.1007/s00423-010-0692-4

15. Lorenz K, Abuazab M, Sekulla C, Nguyen-Thanh P, Brauckhoff M, Dralle H (2010a) Management of lymph fistulas in thyroid surgery. Langenbecks Arch Surg 395. doi:10.1007/s00423-010-0686-2

16. Lorenz K, Sekulla C, Schelle J, Schmeiß B, Brauckhoff M, Dralle $\mathrm{H}$ (2010b) What are normal quantitative parameters of intraoperative neuromonitoring (IONM) in thyroid surgery? Langenbecks Arch Surg 395. doi:10.1007/s00423-010-0691-5

17. Miller B, Gauger P, Hammer G, Thomas G, Doherty G (2010) Proposal for modification of the ENSAT Staging System for adrenocortical carcinoma using tumour grade. Langenbecks Arch Surg 395. doi:10.1007/s00423-010-0698-y

18. Musholt TJ, Schönefeld S, Schwarz CH, Watzka FM, Musholt PB, Fottner C, Weber MM, Springer E, Schad A (2010) Impact of pathognomonic genetic alterations on the prognosis of papillary 
thyroid carcinoma. Langenbecks Arch Surg 395. doi:10.1007/ s00423-010-0682-6

19. Ozolins A, Narbuts Z, Strumfa I, Volanska G, Gardovskis J (2010) Diagnostic utility of immunohistochemical panel in various thyroid pathologies. Langenbecks Arch Surg 395. doi:10.1007/ s00423-010-0690-6

20. Solorzano CC, Sosa JA, Lechner SC, Lew JI, Roman SA (2010) Endocrine surgery: where are we today? A national survey of young endocrine surgeons. Surgery 147:536-541

21. Van Heerden JA (1982) Aspects of surgical endocrinology. World J Surg 6:685

22. Villar JM, Moreno P, Ortega J, Bollo E, Ramírez PC, Muñoz N, Martínez C, Domínguez-Adame E, Sancho J, Miguel del Pino J,
Couselo JM, Carrión A, Candel M, Cáceres N, Octavio JM, Mateo F, Galán L, Ramia JM, Aguiló J, Herrera F (2010) Results of adrenal surgery. Data of a Spanish national survey. Langenbecks Arch Surg 395. doi:10.1007/s00423-010-0697-z

23. Vorländer C, Wolff J, Saalabian S, Lienenlueke RH, Wahl RA (2010) Realtime ultrasound elastography - a non-invasive diagnostic procedure for evaluating dominant thyroid nodules. Langenbecks Arch Surg 395. doi:10.1007/s00423-0100685-3

24. Zerbi A, Capitanio Boninsegna L, Pasquali C, Rindi G, Delle Fave G, Del Chiaro M, Casadei R, Falconi M (2010) Surgical treatment of pancreatic endocrine tumours in Italy: results of a prospective multicenter study on 262 cases 